\title{
Big Five Personality Traits and Occupy Wall Street
}

\author{
Costas Panagopoulos ${ }^{1 *}$, Jonathan L. Lehrfeld ${ }^{2}$ \\ ${ }^{1}$ Department of Political Science, Fordham University, Bronx, NY, USA \\ ${ }^{2}$ Department of Psychology, Fordham University, Bronx, NY, USA \\ Email: *costas@post.harvard.edu
}

Received 18 October 2015; accepted 29 November 2015; published 3 December 2015

Copyright (C) 2015 by authors and Scientific Research Publishing Inc.

This work is licensed under the Creative Commons Attribution International License (CC BY). http://creativecommons.org/licenses/by/4.0/

c) (i) Open Access

\begin{abstract}
We investigated Big Five personality traits for a novel sample of individuals engaged in politically and economically-charged protest activity at the Occupy Wall Street demonstrations in New York City. We gathered data about protesters' personality traits by administering the TIPI battery in a survey conducted in October 2011. We compared distributions of Big Five traits for the sample with population norms. We expected our sample to show higher levels of extraversion, openness, and emotional stability, and lower levels of agreeableness, compared to norms, with no difference in conscientiousness. We found mixed support for our hypotheses: our sample showed higher levels of emotional stability and extraversion, lower levels of agreeableness, and no differences in conscientiousness, but lower levels of openness.
\end{abstract}

\section{Keywords}

Big Five, Political Behavior, Protesters, TIPI, Personality

\section{Introduction}

We investigated Big Five personality traits for a novel sample of individuals engaged in politically and economically-charged protest activity at the Occupy Wall Street demonstrations in New York City in the fall of 2011. The Occupy Wall Street (OWS) protests around the country attracted considerable attention in the political and economic news for much of the latter half of 2011 and beyond. No study of which we are aware has focused on the personality dimensions of this group of individuals. In what follows, we give a brief background of the OWS movement and then proceed to review relevant literature on the relationship of personality to political activities including prior protest movements. We present evidence about the five-factor structure of OWS protesters’ per-

${ }^{*}$ Corresponding author. 
sonalities using the Ten-Item Personality Inventory (TIPI). At first pass, the OWS protesters appear to possess some unique attributes that could help shed light on some of the driving forces behind the movement.

\subsection{Occupy Wall Street: Background}

The OWS movement started in New York City just after the tenth anniversary of the attacks on the World Trade Center on September 11, 2001. The movement largely comprised individuals who desired changes in national economic policy. The movement has been buffeted by reports from various economic groups. One example is an October 26, 2011 report by the Economic Policy Institute that found that the income of the top 1 percent of households in 2007 was 42 times greater than the average incomes of the bottom 90 percent combined (Mishel \& Bivens, 2011). The study also showed that the income of the top 0.1 percent of households was 220 times greater than that of the bottom 90 percent combined. Such reports quickly led to the adoption of the slogan, "We are the 99 percent.” The slogan has become almost instantly recognizable to anybody who follows news coverage of political or economic events.

The OWS movement has also been identified with questionable police activity. Protesters who were wearing masks were arrested near the end of September 2011, and a controversial mass arrest occurred during a march across the Brooklyn Bridge. In the beginning of October 2011, the OWS movement spread to other cities in the US, including Boston, Oakland, San Francisco, and Austin. Police brutality was reported in these and other cities, in addition to New York City. On November 15, 2011, the New York City police began evicting protesters from Zuccotti Park, which had been the center of the OWS protests. At the time of this writing, the fervor surrounding the Occupy Wall Street protests has dissipated somewhat, although demonstrations continue to occur across the nation.

\subsection{Personality, Political Behavior and Protest}

Despite a paucity of published research on the OWS movement, there exists work on the intersection of personality assessment and political behavior that allows us to formulate specific hypotheses about OWS sample and how the distributions of personality traits may differ from the population at large. McClosky and colleagues (McClosky, 1958) found that politically and economically conservative ideology is correlated with higher levels of anxiety and close-mindedness, which presumably would be analogous (when reverse-coded) to the Big Five measures of emotional stability and openness, respectively. Given that a large majority of the OWS protesters in our sample self-identified as "liberal" or "extremely liberal," this could be informative in the current study.

More recently, the Ten Item Personality Inventory (TIPI) (Gosling, Rentfrow, \& Swann, Jr., 2003) was used to show that conscientiousness and emotional stability tended to be associated with more conservative political, economic, and social opinions (Gerber, Huber, Doherty, Dowling, \& Ha, 2010). Conversely, openness was associated with more liberal opinions on all three scales. Agreeableness and extraversion showed more mixed results: when it came to economic opinions, more liberal ideology correlated with more agreeableness and less extraversion, while for social opinions, more liberal ideology correlated with less agreeableness but not a significant change in extraversion. Later, the same authors found substantiating evidence for the associations of liberal ideology with openness, and for conservative ideology with conscientiousness and with emotional stability (Gerber, Huber, Doherty, \& Dowling, 2011). Their study also revealed extraversion to be associated with more conservative ideology. Economic, but not social or political, liberalism, correlated with more agreeableness.

There have also been some relevant studies of personality factors among individuals engaged in political activities. Mondakand colleagues (Mondak, Hibbing, Canache, Seligson, \& Anderson, 2010) found that various forms of political activities are associated with less emotional stability and (sometimes) less conscientiousness. Several authors (Curtin, Stewart, \& Duncan, 2010), (Mondak \& Halperin, 2008), (Steinbrecher \& Schön, 2012), (Vecchione \& Caprara, 2009) have found that more political engagement is associated with more openness and more extraversion.

Concerning protest behaviors more specifically, Abramowitz (Abramowitz, 1973) found that students who engaged in activist behaviors, whether or not politically oriented, scored lower on trait anxiety and psychological distress. People who attended rallies have also been shown to have higher levels of openness, extraversion, and self-efficacy than people who did not attend rallies, but little to no difference in conscientiousness (Mondak, Hibbing, Canache, Seligson, \& Anderson, 2010). Individuals scoring highest in another sam- 
ple of on extraversion were shown to have a $10 \%$ higher likelihood of attending political rallies than those who scored lowest on extraversion (Mondak, 2010). Finally, it has been shown that the likelihood of engaging in political protests was associated with more emotional stability and openness and less agreeableness (Brandstätter \& Opp, 2014).

Using the discussion above and the findings in extant research as a launching pad, we develop the following hypotheses about how the distributions of personality traits among OWS protesters may contrast with the norm sample for the population (these are summarized in Table 1). Overall, we expect: 1) the OWS sample will show higher levels of extraversion, openness, and emotional stability compared to the norm sample, 2) the OWS sample will exhibit lower levels agreeableness compared to the norm sample, 3) there will be no significant difference in conscientiousness between the OWS sample and the norm sample. With regards to our first hypothesis, although there was mixed evidence for the connection between emotional stability and protest behaviors, we put the most weight on the most recent study (Brandstätter \& Opp, 2014), which also used more sophisticated analysis methods to develop the link between this personality trait and protest behavior than the earlier study (Mondak, Hibbing, Canache, Seligson, \& Anderson, 2010). For our second hypothesis, we note that despite some evidence linking liberal ideologies to agreeableness, it is counter to the nature of a protest to expect to find very agreeable people in attendance. Most protesters are there because they harbor passionate beliefs about the topic at hand.

\section{Data and Methodology}

We conducted a survey of the OWS protesters in October 2011. Our survey instrument was a single-sided, onepage questionnaire that was self-administered using paper and pencil. The survey probed respondents about their demographic attributes including age, education, gender, and race as well as political attitudes including presidential and Congressional approval, partisanship, and ideology. Crucially, for this study, the survey also included the Ten-Item Personality Inventory (TIPI) (Gosling, Rentfrow, \& Swann, Jr., 2003). The overall response rate for the survey was $78 \%$.

Our sample comprises 264 individuals who took part in the Occupy Wall Street protests in New York City in October 2011. One hundred and fifty-three (61\%) respondents were male and 97 (39\%) were female. The mean age was approximately 33 years. Sixty-eight respondents (27.2\%) completed high school or obtained a GED, 40 (16\%) completed 2 years of college, 75 (30\%) completed 4 years of college, 55 (22\%) completed some postgraduate work, and the rest did not complete high school. Most respondents (68\%) identified as white, 25 (10\%) as black or African American, 25 (10\%) as Hispanic or Latino, and 18 (7.2\%) as Asian. Additionally, 200 (80\%) identified as left-of-liberal, 98 of whom (39\%) identified as extremely liberal. Lastly, 120 respondents (48\%) were employed full-time or part-time, 63 (25\%) were students, and the rest were unemployed.

\subsection{Ten-Item Personality Inventory (TIPI)}

We administered the TIPI to respondents who participated in the OWS survey. The TIPI is comprised of ten items, with one pair of items for each of the five factors in the Big Five personality model ([14]). One item in each pair is reverse-coded. In the TIPI, the factor typically known as Neuroticism is known as Emotional Stability, and the interpretation is reversed-that is, a low score on Neuroticism would be interpreted as a high score on Emotional Stability. The authors of the TIPI (Gosling, Rentfrow, \& Swann, Jr., 2003) showed that it achieves

Table 1. Comparing OWS sample to norm sample on big five measures.

\begin{tabular}{ccc}
\hline Personality Factor & Hypothesis & Result \\
\hline Emotional stability & + & + \\
Extraversion & + & + \\
Openness & + & - \\
Agreeableness & - & $n s$ \\
Conscientiousness & $n s$ & $n$
\end{tabular}

Note: + indicates higher level of factor in OWS sample than thenorm sample, - indicates lower level of factor in OWS sample than the norm sample, $n s$ indicates no significant difference in factor between OWS sample and the norm sample. 
acceptable levels of convergent validity with other Big Five measures, as well as good test-retest reliability over multiple administrations. For the full measure, see Appendix A in (Gosling, Rentfrow, \& Swann, Jr., 2003).

\subsection{Sampling and Surveying Procedures}

Our systematic observation of the OWS movement was conducted in mid-October 2011, about a month after the demonstrations began and while the protesters were assembled mainly at Zucotti Park in New York City. This was the first survey of the OWS protesters using a rigorous methodology and one of the first surveys overall.

The challenges associated with surveying crowds have been well documented, e.g. by Asher (2004). To maximize reliability, we followed procedures described by Heaney \& Fabio (2007) in studying antiwar protests that took place in the United States in 2004-2005. Like Heaney \& Fabio (2007), we drew nonprobability samples of protesters at Zucotti Park while taking aggressive measures to minimize sampling biases because of nonrandomness.

Two teams of surveyors were assembled and assigned to visit Zucotti Park on two separate days in mid-October. Upon arriving, surveyors spanned out around the perimeter of the crowd at Zucotti Park. Each surveyor was instructed first to choose an individual from the crowd to serve as an "anchor" for selection. These anchors were not approached by the surveyor or invited to participate in the study. Instead, surveyors counted three individuals in a line from the anchor and invited the third person to participate in the survey. The surveyor then counted three persons from that individual and made another invitation. The process continued until ten respondents accepted surveys. It was acknowledge that such a sampling approach may produce biases in the initial selection of the anchors because of the spatial grouping of activists, but we expect these biases are minimized by selecting only individuals close to the anchors (rather than the anchors themselves) and by distributing the surveyors widely throughout the crowd (Heaney \& Fabio, 2007).

\section{Results}

Table 2 presents mean distribution levels for each of the Big Five factors for the OWS sample along with the standard errors associated with these estimates. We also present the corresponding distributions for TIPI norms as reported in Gosling, Rentfrow, \& Swann, Jr. (2003). We deploy a series of Welch two-sample $t$-tests Welch (1947) to compare mean levels of Big Five factors in our sample with the published norms. The Welch $t$-test was used instead of the more traditional independent-samples $t$-test because our data did not satisfy the assumption of homogeneity of variance required by the latter. The Welch $t$-test is robust to heterogeneity of variance, and uses the Welch-Satterthwaite equation to adjust the degrees of freedom of the test accordingly. All $t$-tests were carried out at an alpha level of $\alpha=.05$. Lastly, all effect sizes reported for the $t$-tests are values of Cohen's $d$.

Before reporting the results of our $t$-tests, it is worth noting that the order of the factors from most endorsed to least endorsed in our sample was conscientiousness, emotional stability, agreeableness, extraversion, and openness. Furthermore, using a series of five one-sample $t$-tests, we determined that our participants endorsed all five factors at a significantly higher rate than the neutral point (i.e., neither agree nor disagree, which has a numeric value of 4 on the TIPI; $p<.001$ for all).

We turn next to comparing how personality distributions in the OWS sample compare to extant norms (Table 2, Figure 1). Here we find only partial support for the hypotheses we develop above. We find the OWS sample

Table 2. Comparing OWS sample to norm sample on big five measures.

\begin{tabular}{ccccccc}
\hline \multirow{2}{*}{ Big Five Trait } & \multicolumn{2}{c}{ CCES } & \multicolumn{7}{c}{ OWS } \\
\cline { 2 - 7 } & $M(S E)$ & $N$ & $M(S E)$ & $N$ & $t(d f)$ & Cohen's $d$ \\
\hline Emotional Stability & $5.08(.01)$ & 13,800 & $5.42(.08)$ & 264 & $-3.86(270.92)^{* * *}$ & -.24 \\
Extraversion & $4.25(.01)$ & 13,800 & $4.89(.10)$ & 264 & $-6.31(271.39)^{* * *}$ & -.39 \\
Openness & $5.26(.01)$ & 13,800 & $4.62(.07)$ & 264 & $8.93(272.94)^{* * *}$ & .55 \\
Agreeableness & $5.34(.01)$ & 13,800 & $5.02(.08)$ & 264 & $3.65(271.82)^{* * *}$ & .23 \\
Conscientiousness & $5.72(.01)$ & 13,800 & $5.56(.08)$ & 264 & $1.91(267.84)$ & .12 \\
\hline
\end{tabular}

Note: Negative $t$-values indicate a larger mean value for the OWS sample than the norm sample. ${ }^{* * *}$ signified statistical significance at the $p<.001$ level, two-tailed. 


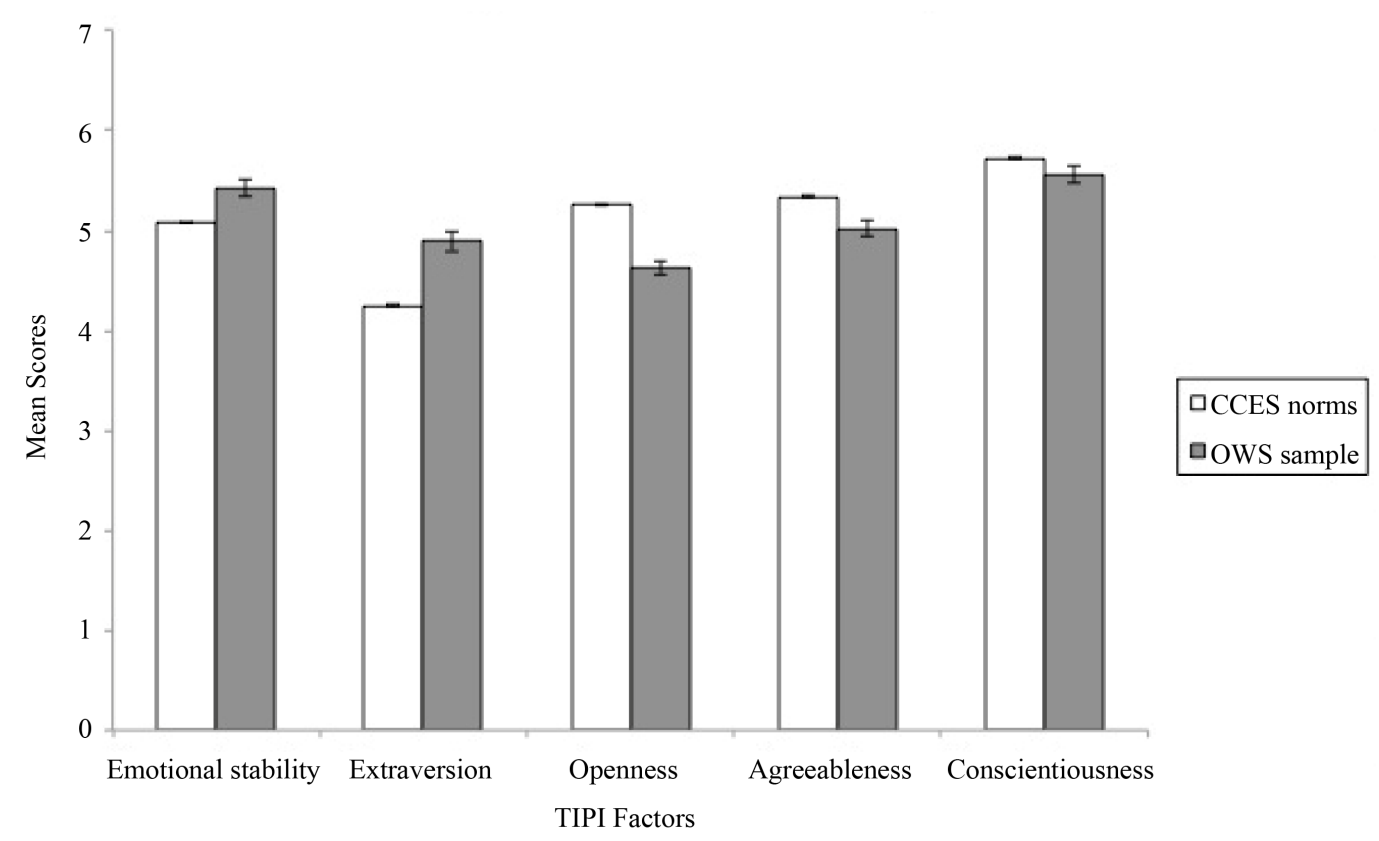

Figure 1. Comparison of CCES norms with OWS sample.

to be higher on emotional stability $(t(270.92)=-3.86, p<.001, d=-.24)$ and extraversion $(t(271.39)=-6.31$, $p<.001, d=-.39$ ) compared to the norm sample; however, we find the OWS sample scored lower on openness $(t(272.94)=8.93, p<.001, d=.55)$ and agreeableness $(t(271.82)=3.65, p<.001, d=.23)$ compared to the norm sample. The difference with respect to conscientiousness between the OWS sample and the norm sample was not statistically significant $(t(267.84)=1.91, n s, d=.12)$.

\section{Discussion and Conclusion}

The main goal of this paper is to present evidence about the distributions of Big Five personality traits for the OWS protesters. We also conduct a series of empirical tests to assess a series of hypotheses about how we expect these distributions to differ from the typical distribution of Big Five traits in the population.

Overall, we find support for most of our hypotheses. Individuals participating in OWS protests did indeed score significantly higher on extraversion and emotional stability, lower on agreeableness, and similarly on conscientiousness compared to the norm sample. In the one case where our results were not consistent with our expectations, we found lower levels of openness than in the norm sample.

One possible explanation for the inconsistent results with respect to openness is the presence of mitigating factors. It has been argued (Mondak, Hibbing, Canache, Seligson, \& Anderson, 2010) that mitigating factors often mediate the strength of the correlations. These mitigating factors, which could include what Opp \& Brandstätter (2010) call incentives, can range from personal in nature (such as having a large stake in the outcome of a political contest or decision) to social (such as wanting to be perceived a certain way by others) to moral/ethical (such as having strong feelings about a candidate's beliefs or the repercussions of an upcoming legislative vote). Indeed, Opp \& Brandstätter (2010) found that incentives explained a moderate portion of variance in protesting behavior in their samples, so when incentives go unmeasured it could be difficult to predict with much precision what the relationship between different personality factors and protesting behavior might be. It was possible that there were mitigating factors relating to personality in our OWS sample that would explain our findings. Additionally, Gallego \& Oberski (2012) found that ability to answer knowledge questions concerning the purpose of the protest, amount of discussions protestors had had with their family members about the issues under protest, and self-efficacy all had a mediating effect on the relationship between openness and engaging in protest behaviors. Such mitigating or mediating factors might explain our findings with respect to openness. Reference Mondak, Hibbing, Canache, Seligson, \& Anderson (2010)'s finding that individuals engaged in protest behaviors score higher on openness is actually rather surprising, given that protesters usually have very strongly-held 
opinions regardless of their political or economic orientations. Perhaps the current study captured a truer picture of the openness factor, whereas Mondak, Hibbing, Canache, Seligson, \& Anderson (2010) had findings confounded by social desirability bias, whereby protesters depicted themselves as open to new ideas to counteract the stereotypical image of protesters as radical in their opinions. Further research should be conducted to investigate these relationships.

Mondak also discusses the role of self-efficacy in determining whether individuals who score high on conscientiousness engage in protest behaviors (Mondak, 2010). The mediating role of self-efficacy is analogous to the mediating role of other possible incentives or mitigating factors, examples of which are given above. Namely, if individuals think that engaging in protests has the possibility of effecting change, we say that they have high levels of self-efficacy. Then, an individual who scores high on self-efficacy and conscientiousness is more likely to engage in political protests, while an individual who scores low on self-efficacy and high on conscientiousness is less likely to engage in political protest. After all, if one thinks one does not have the power to effect change, why would one bother spending all the effort to protest? This mediating effect of self-efficacy on conscientiousness acts as a neutralizer on the relationship of conscientiousness with protest activities, and that is why we see our hypothesized null effect for this factor.

In conclusion, we present research on a novel sample of Occupy Wall Street protesters in the New York City area. To our knowledge, the personality dimensions of this group of individuals have never before been studied. We find OWS protesters to be more emotionally stable and extraverted than what is typical for the population at large, but less open and agreeable. We find no differences in levels of conscientiousness. Future research may leverage data about respondents' motivations for participating in protests and conduct mediation analyses to link personality factors with incentives.

\section{References}

Abramowitz, S. I. (1973). The Comparative Competence-Adjustment of Student Left Social-Political Activists. Journal of Personality, 41, 244-260.

Asher, H. (2004). Polling and the Public (6th ed.). Washington DC: CQ Press.

Brandstätter, H., \& Opp, K.-D. (2014). Personality Traits (“Big Five”) and the Propensity to Political Protest: Alternative Models. Political Psychology, 35, 515-537.

Curtin, N., Stewart, A. J., \& Duncan, L. E. (2010). What Makes the Political Personal? Openness, Personal Political Salience, and Activism. Journal of Personality, 78, 943-968.

Gallego, A., \& Oberski, D. (2012). Personality and Political Participation: The Mediation Hypothesis. Political Behavior, 34, 425-451.

Gerber, A. S., Huber, G. A., Doherty, D., \& Dowling, C. M. (2011). The Big Five Personality Traits in the Political Arena. Annual Review of Political Science, 14, 265-287.

Gerber, A. S., Huber, G. A., Doherty, D., Dowling, C. M., \& Ha, S. E. (2010). Personality and Political Attitudes: Relationships across Issue Domains and Political Contexts. American Political Science Review, 104, 111-133.

Gosling, S. D., Rentfrow, P. J., \& Swann, Jr., W. B. (2003). A Very Brief Measure of the Big-Five Personality Domains. Journal of Research in Personality, 37, 504-528.

Heaney, M., \& Fabio, R. (2007). Partisans, Nonpartisans, and the Antiwar Movement in the United States. American Politics Research, 35, 431-464.

McClosky, H. (1958). Conservatism and Personality. American Political Science Review, 52, 27-45.

Mishel, L., \& Bivens, J. (2011). Occupy Wall Streeters Are Right about Skewed Economic Rewards in the United States (Briefing Paper \#331). The Economic Policy Institute Website. http://www.epi.org/publication/bp331-occupy-wall-street/

Mondak, J. J. (2010). Personality and the Foundations of Political Behavior. New York, NY: Cambridge University Press.

Mondak, J. J., \& Halperin, K. D. (2008). A Framework for the Study of Personality and Political Behavior. British Journal of Political Science, 38, 335-362.

Mondak, J. J., Hibbing, M. V., Canache, D., Seligson, M. A., \& Anderson, M. R. (2010). Personality and Civic Engagement: An Integrative Framework for the Study of Trait Effects on Political Behavior. American Political Science Review, 104, 85-110.

Opp, K.-D., \& Brandstätter, H. (2010). Political Protest and Personality Traits: A Neglected Link. Mobilization: An International Journal, 15, 323-346.

Steinbrecher, M., \& Schön, H. (2012). Personality and Political Participation against the Background of the German Federal 
Election 2009. Journal of Political Psychology, 12, 30-51.

Vecchione, M., \& Caprara, G. (2009). Personality Determinants of Political Participation: The Contribution of Traits and Self-Efficacy Beliefs. Personality and Individual Differences, 46, 487-492.

Welch, B. L. (1947). The Generalization of Student's Problem when Several Different Population Variances Are Involved. Biometrika, 34, 28-35. 